\title{
Effect of Manufacturing Processes and Welding Type on Quasi- static and Dynamic Responses of Aluminum Alloys: Experiments and Modeling
}

\author{
Muneer Baig ${ }^{1}$ Akhtar S. Khan ${ }^{2} \cdot$ Shi-Hoon $\mathrm{Choi}^{3} \cdot$ E. Lee $^{3}$
}

Received: 8 March 2015 / Accepted: 8 June 2015/Published online: 18 June 2015

(C) Society for Experimental Mechanics, Inc 2015

\begin{abstract}
Measured responses of two aluminum alloys over a wide range of strain-rates $\left(10^{-5}\right.$ to $\left.10^{3} \mathrm{~s}^{-1}\right)$ and temperatures are presented. The aluminum alloys include AA5182-O and AL6111-T4. A tensile spilt Hopkinson pressure bar was used for the dynamic experiments. The aluminum AA5182-O alloy (manufactured using continuous casting and direct chilling processes) including its first and second generation gas tungsten arc welded and friction stir welded TWB's exhibited negative strain-rate sensitivity. AL6111-T4 is found to have positive strain-rate sensitivity. The Khan-Huang-Liang constitutive model is shown to correlate and predict the observed responses reasonably well. The texture evolution of the AA5182-O and AL6111-T4 sheets during uniaxial tension is investigated using the EBSD technique and full-constraint polycrystal model. It is observed through the EBSD analysis that, the stable orientation is strongly dependent on the initial texture components.
\end{abstract}

Keywords AA5182-O - AL6111-T4 - Quasi-static and dynamic response - Tensile split Hopkinson bar · EBSD

Muneer Baig

bmuneer@ksu.edu.sa

1 AMI-CEREM-Center of Excellence for Research in Engineering Materials, King Saud University, Riyadh 11421, Kingdom of Saudi Arabia

2 Department of Mechanical Engineering, University of Maryland Baltimore County, Baltimore, MD 21250, USA

3 Department of Materials Science and Metallurgical Engineering, Sunchon National University, Sunchon 540-742, Korea

\section{Introduction}

Increasing the fuel efficiency while maintaining the safety of the occupants has been an area of interest for the automotive industry. To incorporate this desirable feature, various alternatives have been explored (e.g. hybrid cars, aerodynamic design etc.). One way to improve the fuel efficiency is to reduce the weight of the automobile. Consequently, aluminum alloys are gaining attention due to their high strength to weight ratio [1]. One of the major development in the automotive industry is the introduction of Ford F-150 all aluminum truck. It is worthwhile to note here that the overall reduction in weight of the F-150 truck is around $317 \mathrm{~kg}$ (700 pounds). This reduction in weight implies an increase in the fuel economy of the automotive. Currently, aluminum alloys are being used for non-structural components such as deck lids and hoods with a possibility of more and more use in future [2]. Also, the weight of the automobile can be successfully reduced through the use of tailor welded blanks (TWB) technique, which results in less number of parts, fewer spot welds and improved structural integrity. TWB technique consists of joining two or more materials of different thicknesses to produce one sheet of variable thickness. Although this technique results in effective use of material, it suffers from major drawback because of the presence of a weld.

In general, aluminum alloys exhibit good strength and stiffness but has comparatively poor formability at room temperature than typical steel [3]. Hence, enhancing the formability of aluminum alloys is currently an area of considerable interest in the automotive industry and the research community. It was reported in the literature that the formability of aluminum alloys can be increased by warm forming methods [4-8]. Also, Warm forming above a critical temperature may negate the serrated flow 
behavior [dynamic strain aging/Portevin-LeChatelier (PLC) effect] observed on certain $\mathrm{Al}-\mathrm{Mg}$ alloy [6].

Hughes et al. [9], in their efforts to understand the material behavior of AA 5182-O as a function of strain rate and temperature, performed a series compression experiments in the strain rate and temperature regimes of $10^{-3}$ to $10^{0} \mathrm{~s}^{-1}$ and $22-550{ }^{\circ} \mathrm{C}$, respectively. Based on these results they concluded that the deformation mechanism is governed by dynamic strain aging at room temperature. Further, negative strain rate sensitivity was observed at all strain rates. Davies et al. [10] reported their work in developing theoretical forming limit diagrams (FLDs) for weld materials. They used power law along with the Hosford yield criteria to obtain right-hand-side of FLD. The authors concluded that AA5182-O exhibit near zero strain rate sensitivity and consequently used a strain rate insensitive constitutive model in their calculation of theoretical FLD. Picu et al. [1], investigated the effect of dynamic strain aging on ductility of the aluminum alloy AA5182-O. Experimental results at temperatures ranging from -120 to $150{ }^{\circ} \mathrm{C}$, and strain-rates from $10^{-6}$ to $10^{-1} \mathrm{~s}^{-1}$, were reported. They observed that AA5182-O exhibit negative strain rate sensitivity in the temperature regime of -80 to $110{ }^{\circ} \mathrm{C}$.

The structural components of automobiles are subjected to quasi-static and dynamic loading rates during their manufacturing processes, as well as in an accident. As such, it is imperative to understand the material behavior under these loading rates. With much of the progress done in determination of the material behavior under quasi-static loading rates, it was deemed important to determine material response under high rates of loading. Since these materials are in the form of thin sheets, Kolsky [11] compression split Hopkinson bar (SHPB) was modified by many researches to perform dynamic high strain-rate tensile experiments. While the compression configuration does not need any mechanism to grip the specimen, the tensile configuration needs a grip to hold the specimen and transmit the tensile pulse from incident to transmitted bar. The major problem in designing a high strain-rate tensile apparatus is the design of the griping mechanism. It was mentioned by Kang et al. [12] that grips should be able to clamp the specimen without sliding and reduce the mechanical impedance so that the wave propagation is not dissipative. Harding et al. [13] used a tension Hopkinson bar in which the compressive pulse was sent in a tube surrounding a solid inner rod. Although, this technique was simple to use it had a major drawback of wave dispersion at the mechanical joint. Similar setup was later used by Hauser et al. [14]. Later, Lindholm and Yeakly [15] and Lindholm [16] developed a technique where they used two Hopkinson bars; one being solid and the other being hollow. They performed high strain-rate tensile experiments on a hat shaped specimen. The technique was simple to use but it was reported that, making a hat type specimen was a complicated process. Nicholas [17, 18] modified the split Hopkinson configuration by using a split-shoulder (collar) arrangement surrounding a specimen threaded to the two bars. The compressive pulse was generated on the incident bar which traveled through the split shoulder (collar) to the transmitted bar, without going through the specimen. During passage of reflected tensile wave generated a tension in the specimen; the collar was inactive this time. In this case, wave distortion occurred due to the clearance of the threaded region [19]. Huh et al. [19] developed a tensile split Hopkinson pressure bar (SHPB) in which a hollow striker tube is fired from gas gun and impacts an anvil which is a part of the incident bar. At the impact, a tensile pulse is generated in incident bar and propagates through the specimen to the transmitted bar. Staab and Gilat [20] proposed a new method in which the portion on the incident bar was clamped using a clamping mechanism. The clamped portion was then pre-tensioned. The clamp was suddenly released to generate a tensile pulse in the incident bar, which was transmitted to the other bar through the specimen. They named this method as "direct tension".

The strain rate sensitivity of AA5182-O and on different types of welds in TWBs, in the dynamic regime was not fully explored. The present investigation was made to address this void. The dynamic experiments were performed by using modified tensile split Hopkinson pressure bar, using a combination of Nicholas [17, 18] and Huh et al. [19] techniques, to investigate the strain-rate sensitivity of AA5182 and AL6111-T4, during tensile loading, including welded alloy as well. The KHL constitutive model was used to correlate and predict the experimental response. Also, the texture evolution of AA5182-O and AL6111-T4 sheets is investigated using electron backscattered diffraction (EBSD) technique. The ODF analysis was performed with respect to the sample symmetry defined by rolling direction (RD), transverse direction (TD), and normal direction (ND). To understand the stable orientation developed in the quasi-static and dynamic specimens, the rotation rate map and orientation stability of typical texture components were theoretically evaluated using a full-constraints polycrystal model [21, $22]$.

\section{Experimental Procedures}

\section{Material}

All the specimens used in this study were made from sheet and were supplied by Pacific Northwest National Laboratories. The initial chemical composition of the base 
materials used in the current investigation is shown in Table 1 (AA 5182-O) and Table 2 (Al6111-T4). The two materials investigated are of significant interest to the automotive industry which is inclined to reduce the weight of automobiles and increase its fuel economy. The specimens were machined using wire EDM. The typical sample geometry used in this study is shown in Fig. 1. The samples were obtained from different co-ordinates (locations) of the same sheet. The gage section of the welded samples consists of nearly $100 \%$ of the weld. All the quasi-static experiments $\left(10^{-5}\right.$ to $\left.10^{0} \mathrm{~s}^{-1}\right)$ were performed using MTS servo hydraulic axial-torsional material testing machine and all the dynamic experiments $\left(10^{2}\right.$ to $\left.10^{3} \mathrm{~s}^{-1}\right)$ were performed on a tensile SHPB apparatus. The EBSD specimens were prepared using colloidal silica as the polishing medium for the intermediate stage. The final specimens were prepared by electro-polishing in A2 electrolyte for the final stage. The EBSD data were analyzed using TSL software to evaluate 3-D ODF. For the undeformed and deformed specimens, the measurement step size and the scanned area were $1 \mu \mathrm{m}$ and $600 \mu \mathrm{m}$ (RD) $\times 300 \mu \mathrm{m}$ (ND), respectively.

\section{Quasi-static Monotonic and Strain-Rate Jump Experiments}

Quasi-static monotonic tensile experiments were performed at the strain-rate of $10^{-4} \mathrm{~s}^{-1}$. A high elongation uniaxial strain gage, bonded on the gage section of the

Table 1 Chemical composition of AA5182-O

\begin{tabular}{lllll}
\hline Material & $\mathrm{Al}$ & $\mathrm{Mg}$ & $\mathrm{Mn}$ & Others \\
\hline AA5182-O & 95.2 & 4.2 & 0.3 & 0.3 \\
\hline
\end{tabular}

Table 2 Chemical composition of Al6111-T4

\begin{tabular}{lllllll}
\hline Material & $\mathrm{Al}$ & $\mathrm{Mg}$ & $\mathrm{Si}$ & $\mathrm{Cu}$ & $\mathrm{Mn}$ & Others \\
\hline Al6111-T4 & 97.5 & 0.6 & 0.5 & 0.6 & 0.2 & 0.1 \\
\hline
\end{tabular}

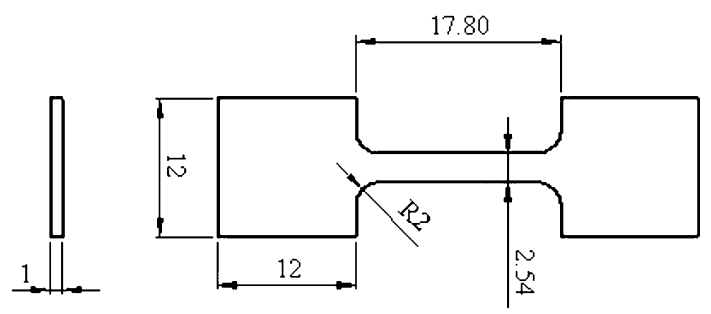

Fig. 1 Typical tension specimen geometry. All dimensions are in $\mathrm{mm}$ specimen, was used to measure strain. The load obtained from the MTS load transducer was used to calculate the stress. Specimen taken from different locations in the sheet may have slight variations; the observed responses due to these variations may compete or mask the observed strain rate sensitivity. Thus, to eliminate the effects due to variations in specimens, strain-rate jump experiments were preformed in each sample where strain rate was changed during the experiment. The strain-rate jump experiments were started initially at the strain-rate of $10^{-5} \mathrm{~s}^{-1}$ and after 3-4\% true strain, the strain-rate was changed to $10^{-1} \mathrm{~s}^{-1}$ and loading was continued for another $4-5 \%$ true strain. Finally, the strain rate was changed back to $10^{-5} \mathrm{~s}^{-1}$ and the loading was continued until failure. In some experiments, the sequence was reversed to observe consistent strain-rate sensitivity. Also, in some cases, the specimen was unloaded after $2-3 \%$ of deformation at a strain-rate of $10^{-5} \mathrm{~s}^{-1}$. It was loaded in a tensile SHB to a several fold higher strain rate $\left(>10^{2} \mathrm{~s}^{-1}\right)$ to failure.

\section{Dynamic (High Loading Rate) Tensile Experiments}

Dynamic tensile experiments were performed on AA5182$\mathrm{O}$ and AL6111-T4 using modified version of Nicholas [17, 18] split Hopkinson pressure bar (SHPB). The Nicholas $[17,18]$ version was similar to regular compression SHPB, the difference being an additional split collar mechanism. The split collar consisted of a two semi-circular half portions (when joined together form a circular rod with diameter equal to the incident or transmitted bars and the length equal to the gage section of the sample) made from the same material as the incident bar. The assembly consisted of a slot (with the thickness and width equal to the dimensions of the gage section of the specimen) machined on the two inner surfaces. The specimens experimented were solid tensile samples with threaded ends. The gage section of the samples was confined within the split collar. The experimental setup was used to perform dynamic experiments by generating compressive waves in the incident bar which travel through the split collar to the transmitted bar. The compressive wave upon reaching the free end of the transmitted bar switches to tensile wave which travels through the transmitted bar to load the specimen in tension. Since the tensile loading is from the free end of the transmitted bar, it can be considered as indirect tension. Later, Huh et al. [19] studied dynamic tensile behavior of various steel samples. They designed an experimental setup to perform direct dynamic tensile experiments on sheet samples. The sample gripping end of the incident and transmitted bar each consisted of a slot (equal to thickness of specimen) and a hole. A matching hole was machined on the gripping portion of the tensile sheet sample. The sample was gripped between the incident and the 
transmitted bar using a bolt an nut assembly that passed through the specimen hole.

The experimental setup used in the current investigation is shown in Fig. 2. It is a combination of both the experimental setup wherein; the loading mechanism is similar to the setup used by Nicholas (indirect tensile) with split collar and the gripping of the sheet sample was based nut and bolt assembly used by Huh et al. [19]. The typical strain rates that can be achieved using this technique ranged from 500-10 $\mathrm{s}^{-1}$. The incident and transmitted bars (made from Al 2024-T4) were $12.7 \mathrm{~mm}$ in diameter and were $1.8 \mathrm{~m}$ and $1.3 \mathrm{~m}$ long, respectively. The diameter of the projectile was same as that of incident or transmitted bar and the length was $0.61 \mathrm{~m}$. The nut and bolt assembly were made of the same material (Al 2024-T4) as that of the bars. Slots of almost the same thickness as of the specimen being tested were machined on the bar to hold the specimen. After inserting the specimen in the slot, additional force was applied while tightening the bolts resulting in closing the slot so that any air gap through the cross-section was minimized. A split collar was used around the specimen, and designed in such a way that there was almost no gap left between the bar ends and the collar, once the specimen was in place. The length of the split collar was varied, to accommodate specimens with different gage lengths.

\section{Constitutive Model and Theoretical Analysis}

KHL model (Khan and Liang [23]; Khan et al. [24]; Khan et al. [25]) was used to model the experimental response of these materials. The KHL model is as follows:

$\sigma=\left[A+B\left(1-\frac{\ln \dot{\varepsilon}}{\ln D_{0}^{p}}\right)^{n_{1}}\left(\varepsilon_{p}\right)^{n_{0}}\right]\left(\frac{\dot{\varepsilon}}{\dot{\varepsilon}^{*}}\right)^{c}\left(\frac{T_{m}-T}{T_{m}-T_{r}}\right)^{m}$,

where $\sigma$ is the stress and $\varepsilon^{p}$ is the plastic strain. $A, B, n_{1}, n_{0}$, $C, m$ are material constants. A is the yield stress of the material at the strain-rate of $10^{0} \mathrm{~s}^{-1} . B$ and $n_{1}$ represent the work hardening coefficient and strain-rate sensitivity of the work hardening, respectively. $n_{0}$ is the work hardening exponent, $C$ is the strain-rate sensitivity exponent and $m$ represents the temperature sensitivity parameter. $T_{m}, T_{r}, T$ are the melting $(873 \mathrm{~K})$, reference (room temperature) and current (experiment) temperatures, respectively. $D_{0}^{p}$ is

Fig. 2 The schematic of SHPB used in the current investigation (a) the gripping end of the incident and transmitted bar (b)

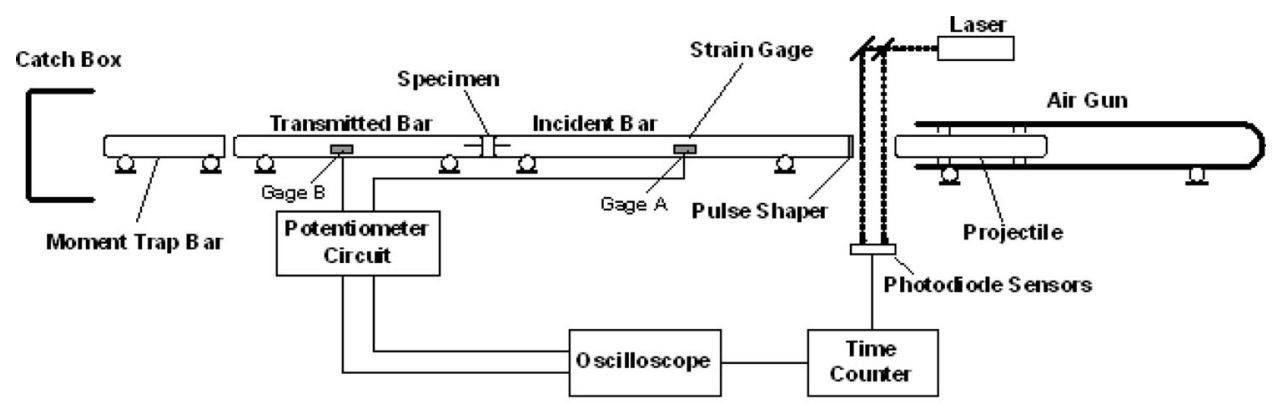

(a)

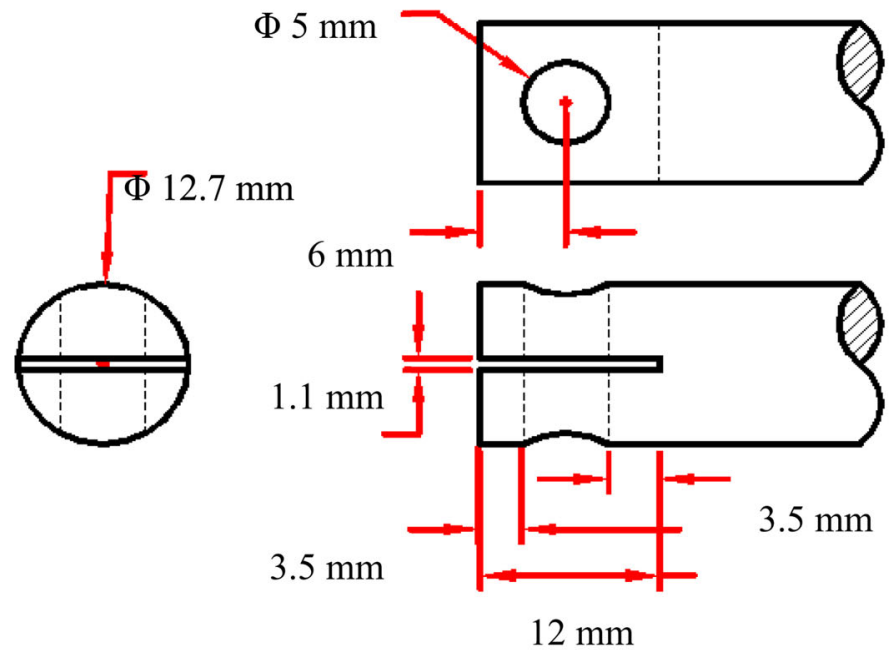

(b) 
arbitrarily chosen upper bound strain-rate, taken to be $10^{6} \mathrm{~s}^{-1} . \dot{\varepsilon}$ represents the experimental strain-rate and $\dot{\varepsilon}^{*}$ is the normalizing strain-rate parameter, usually taken as $1 / \mathrm{s}$. The step by step procedure to obtain the material constants for the KHL model can be found in Khan and Liang [23].

A full-constraints polycrystal model [21, 22] was used to predict the rotation rate map and orientation stability during uniaxial tension. The loading direction of AA5182-O and AL6111-T4 sheets was parallel to the TD. Deformation rate tensor, $\mathbf{D}$ along the TD can be described with respect to the sample coordinate system as a function of plastic strain ratio.

$$
\begin{aligned}
\mathbf{D} & =\left[\begin{array}{ccc}
D_{R D} & 0 & 0 \\
0 & D_{T D} & 0 \\
0 & 0 & D_{N D}
\end{array}\right] \\
& =D_{T D}\left[\begin{array}{ccc}
-\frac{R_{T D}}{R_{T D}+1} & 0 & 0 \\
0 & 1 & 0 \\
0 & 0 & -\frac{1}{R_{T D}+1}
\end{array}\right]
\end{aligned}
$$

In the present study, the plastic strain ratio was determined theoretically using a visco-plastic self-consistent (VPSC) polycrystal model under a stress boundary condition [26]. The estimated R-values of the IF-HSS sheet were 0.61 and 0.83 , respectively. The deformation of rate sensitive polycrystal is usually modeled by a power law relationship between the shear rate $\dot{\gamma}_{\mathrm{s}}$ and the resolved shear stress $\tau^{\mathrm{s}}$ on a slip system $\mathrm{s}$.

$\tau^{\mathrm{s}}=\tau_{\mathrm{o}} \operatorname{sgn}\left(\dot{\gamma}_{\mathrm{s}}\right)\left|\frac{\dot{\gamma}_{\mathrm{s}}}{\dot{\gamma}_{\mathrm{o}}}\right|^{\mathrm{m}}=\tau_{\mathrm{o}} \frac{\dot{\gamma}_{\mathrm{s}}}{\dot{\gamma}_{\mathrm{o}}}\left|\frac{\dot{\gamma}_{\mathrm{s}}}{\dot{\gamma}_{\mathrm{o}}}\right|^{\mathrm{m}-1}$

where $m$ is the rate sensitivity parameter, $\tau_{0}$ is a reference shear stress and $\dot{\gamma}_{o}$ is a reference shear rate. The sign term in Eq. (3) means that the shear rate has the same sign with the resolved shear stress. The resolved shear stress is related to the Cauchy stress tensor $\sigma_{i j}$ of the crystal through the following relation.

$\tau^{\mathrm{s}}=\mathrm{m}_{\mathrm{ij}}^{\mathrm{s}} \sigma_{\mathrm{ij}}$

where the Schmid tensor $m_{i j}^{s}\left(=b_{i}^{s} n_{j}^{s}\right)$ is defined with the component of the unit vector $n_{j}^{s}$ which is normal to the slip plane and the unit vector $b_{i}^{s}$ which is parallel to the slip direction of the slip system $\mathrm{s}$. When the elastic deformation is ignored, the vectors $n_{j}^{s}$ and $b_{i}^{s}$ are orthogonal. The component of the strain rate tensor $D_{i j}$ associated to the given stress tensor $\sigma_{\mathrm{ij}}$ is

$$
\begin{aligned}
\mathrm{D}_{\mathrm{ij}} & =\sum_{\mathrm{s}} \frac{1}{2}\left(\mathrm{~m}_{\mathrm{ij}}^{\mathrm{s}}+\mathrm{m}_{\mathrm{ji}}^{\mathrm{s}}\right) \dot{\gamma}_{\mathrm{s}} \\
& =\frac{\dot{\gamma}_{\mathrm{o}}}{\tau_{\mathrm{o}}^{1 / \mathrm{m}}} \sum_{\mathrm{s}} \frac{1}{2}\left(\mathrm{~m}_{\mathrm{ij}}^{\mathrm{s}}+\mathrm{m}_{\mathrm{ji}}^{\mathrm{s}}\right) \mathrm{m}_{\mathrm{kl}}^{\mathrm{s}} \sigma_{\mathrm{kl}}\left|\mathrm{m}_{\mathrm{pq}}^{\mathrm{s}} \sigma_{\mathrm{pq}}\right|^{\frac{1}{\mathrm{~m}}-1}
\end{aligned}
$$

It should be noted that the strain rate is deduced from the following stress potential (Toth et al. [21]; Choi et al. [22])

$$
\begin{gathered}
\mathrm{F}\left(\sigma_{\mathrm{ij}}\right)=\frac{\mathrm{m}}{(\mathrm{m}+1)} \frac{\dot{\gamma}_{\mathrm{o}}}{\tau_{o}^{1 / \mathrm{m}}} \sum_{\mathrm{s}}\left|\frac{1}{2}\left(\mathrm{~m}_{\mathrm{ij}}^{\mathrm{s}}+\mathrm{m}_{\mathrm{ji}}^{\mathrm{s}}\right) \sigma_{\mathrm{ij}}\right|^{\frac{1}{\mathrm{~m}}+1} \\
=\frac{\mathrm{m}}{(1+\mathrm{m})} \dot{\mathrm{W}}\left(\sigma_{\mathrm{ij}}\right) \\
\text { and } \mathrm{D}_{\mathrm{ij}}=\frac{\partial \mathrm{F}\left(\sigma_{\mathrm{ij}}\right)}{\partial \sigma_{\mathrm{ij}}}
\end{gathered}
$$

where $\dot{\mathbf{W}}\left(\sigma_{i j}\right)$ is the rate of plastic work according to the prescribed strain rate $D_{i j}$. The stress state which satisfies the above equation for a given strain rate can be numerically obtained by the Newton-Raphson method. The lattice rotation rate $\dot{\Omega}_{i j}$ with respect to the laboratory is given as follows.

$\dot{\Omega}_{\mathrm{ij}}=\mathrm{D}_{\mathrm{ij}}-\sum_{\mathrm{s}} \mathrm{m}_{\mathrm{ij}}^{\mathrm{s}} \dot{\gamma}_{\mathrm{s}}$

The lattice rotation rate can be obtained from the prescribed strain rate tensor $\mathrm{D}_{\mathrm{ij}}$ and the calculated shear rate $\dot{\gamma}_{\mathrm{s}}$. The Euler angles $\left(\phi_{1}, \Phi, \phi_{2}\right)$ of the individual orientations should be updated according to the lattice rotation rate $\dot{\mathbf{g}}\left(\dot{\phi}_{1}, \dot{\Phi}, \dot{\phi}_{2}\right)$ as

$$
\begin{aligned}
\dot{\phi}_{1} & =\left(\dot{\Omega}_{32} \sin \phi_{2}+\dot{\Omega}_{13} \cos \phi_{2}\right) / \sin \Phi \\
\dot{\Phi} & =\dot{\Omega}_{32} \cos \phi_{2}-\dot{\Omega}_{13} \sin \phi_{2} \\
\dot{\phi}_{2} & =\dot{\Omega}_{21}-\dot{\phi}_{1} \cos \Phi
\end{aligned}
$$

The kinematic stability of an orientation can be estimated using two parameters. The first parameter is the condition for either convergence or divergence of an orientation in 3-D Euler space. The condition can be expressed by divergence of the rotation field, $\dot{\mathbf{g}}=$ $\left(\dot{\phi}_{1}, \dot{\Phi}, \dot{\phi}_{2}\right)$ as follows (Choi et al. [27])

$\operatorname{div} \dot{\mathbf{g}}=\frac{\partial \dot{\phi}_{1}}{\partial \phi_{1}}+\frac{\partial \dot{\Phi}}{\partial \Phi}+\frac{\partial \dot{\phi}_{2}}{\partial \phi_{2}}$

The conditions for convergence and divergence are $\operatorname{div} \dot{\mathbf{g}}<0$ and $\operatorname{div} \dot{\mathbf{g}}>0$, respectively. $\operatorname{div} \dot{\mathbf{g}}<0$ indicates that more orientations around $g$ rotate toward $g$. The second parameter is the relative magnitude of the lattice rotation rate of the orientation in 3-D Euler space. The stability parameter can be expressed in terms of the lattice rotation rate (Choi et al. [27])

$\mathrm{S}=\ln \left(\frac{\dot{\varepsilon}_{\mathrm{eq}}}{|\dot{\Omega}|}\right)=\ln \left(\frac{\dot{\varepsilon}_{\mathrm{eq}}}{\left[\dot{\Omega}_{32}^{2}+\dot{\Omega}_{13}^{2}+\dot{\Omega}_{21}^{2}\right]^{1 / 2}}\right)$

where $\dot{\varepsilon}_{e q}$ is the von Mises equivalent strain rate for the deformation mode of interest. Kinematically stable orientations have high values of $\mathrm{S}$ compared with the unstable orientation. 


\section{Results and Discussion}

Symbol in Fig. 3, show the responses of base sheet (AA5182-O), first and second generation gas tungsten arc weld (GTAW), and friction stir weld (FSW) samples at a dynamic strain-rate of approximately $1000 \mathrm{~s}^{-1}$. It is observed that the Friction Stir Weld samples (FSW) has higher strength in comparison with material obtained in other welds. The base sheet materials obtained in rolling direction, irrespective of manufacturing processes, exhibit more ductility than welded materials. Also, the first generation GTAW samples exhibit higher strength but lower ductility in comparison with second generation GTAW samples.

Symbols in Fig. 4, show the responses of base sheet [manufactured through continuous casting (CC) process] during a strain-rate jump experiments at room temperature at three different strain-rates. The axis of samples (and the
Fig. 3 True stress-plastic strain responses of base sheet (AA5182-O), first and second generation GTAW, and friction stir samples at high strain-rates of $\left(700-1000 \mathrm{~s}^{-1}\right)$
Fig. 4 True stress-plastic strain responses of base sheet (AA5182-O) manufactured by CC process, with loading axis along the rolling direction
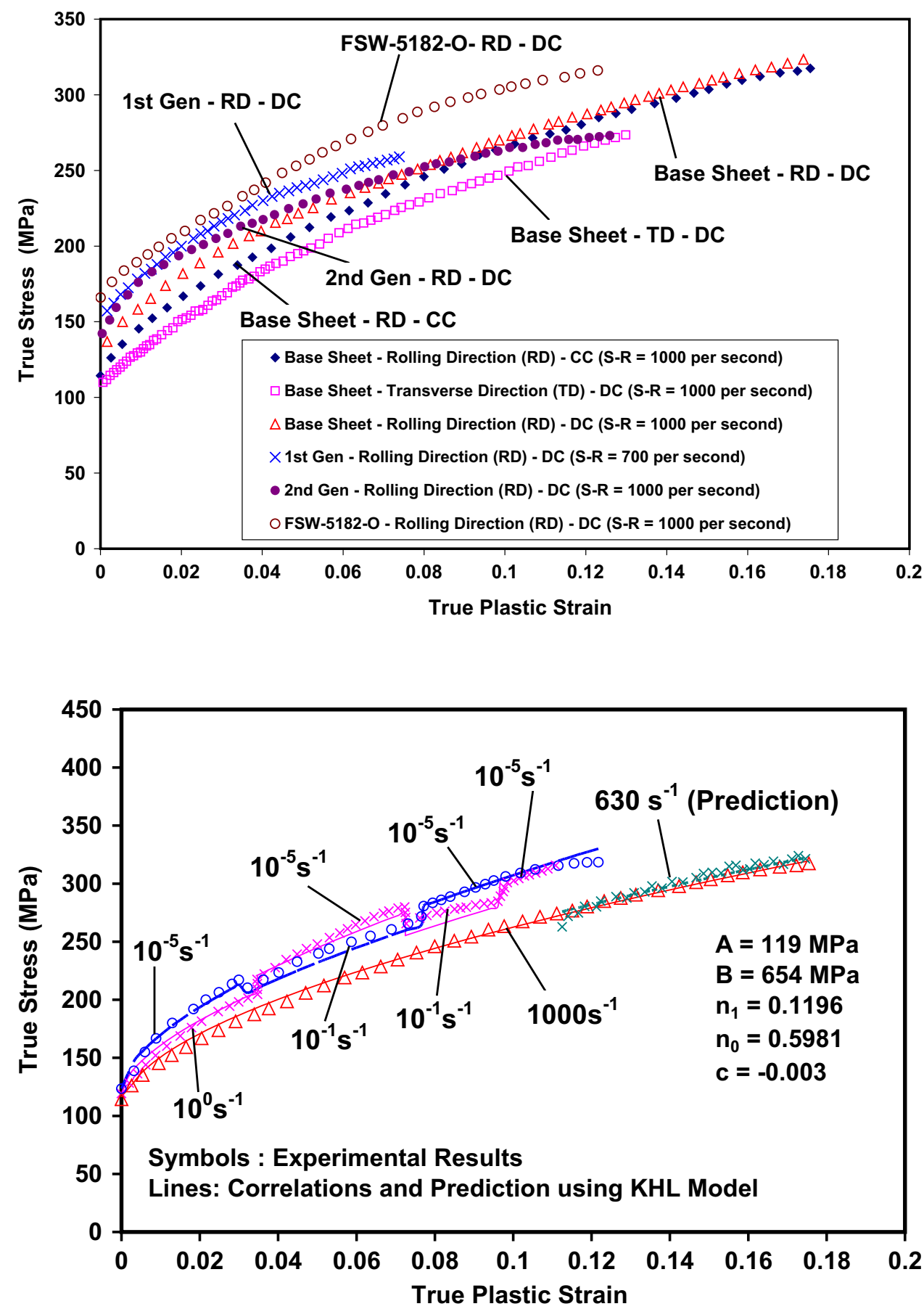
loading direction) was aligned with the rolling direction of the base sheet. As seen in Fig. 4, the base material (AA5182-O) exhibit negative strain-rate sensitivity. Picu et al. [1] also observed similar behavior (but at low strain rates) and concluded that the negative sensitivity of AA5182 was due to the interaction of solute atoms with dislocations. These interactions are associated to dynamic strain ageing (DSA). The DSA mechanism may lead to clustering of solute atoms which provides resistance to dislocation motion. The average size of clusters is dependent on strain-rate. At high strain-rates, the clusters are smaller in size and do not offer significant resistance to the dislocation motion. On the other hand, at a lower strain-rate there is enough time to form large clusters which provide resistance to dislocation motion. Hence, negative strainrate sensitivity is observed in this alloy (Picu et al. [1]). Further, in this Fig. 4 it is observed that the ductility of the base sheet material increases with strain-rate. The experimental results from Fig. 4 are used to obtain the material constants for the KHL constitutive model and the corresponding correlations (lines) are also shown in the same figure along with the experimental results (symbols). These material parameters obtained for the base sheet material (manufactured by using CC technique) are shown in the insert of the Fig. 4. The experimental data at a strain rate of $630 \mathrm{~s}^{-1}$ was not used to determine the material constants. Without changing these constants, the experimental result at the strain-rate of $630 \mathrm{~s}^{-1}$ is predicted. The prediction is observed to be very close to the experimental values.
Figure 5 shows the similar results for the base sheet AA5182-O, manufactured through direct chilling (DC) process. The loading axis of these samples was along the rolling direction of the sheet. The material again exhibits negative strain-rate sensitivity. The KHL model is shown to correlate and predict the observed responses well.

Figure $6 \mathrm{a}, \mathrm{b}$ shows the measured responses at room temperature (for different strain-rates), and at different temperatures (at a constant strain-rate of $10^{-3} \mathrm{~s}^{-1}$ ), along with correlations and prediction of base sheet (also manufactured through DC process). The loading axis of samples was along the transverse to rolling direction of the sheet. An increase in ductility from $\sim 18 \%$ strain at room temperature to $\sim 30 \%$ strain at high temperature can be observed. The responses are close to model prediction. From Figs. 4, 5 and 6 it appears that the base sheet aluminum alloy AA5182-O, irrespective of manufacturing process, has negative strain-rate sensitivity. Also the failure strain (at room temperature) does not seem to be significantly effected by the manufacturing process. On comparing Figs. 4 and 5 it is observed that the material obtained through DC process has higher strength than the one obtained using the CC process. On the other hand, a comparison of Figs. 5 and $6 a$, the strength in rolling direction is higher than the transverse direction.

Figures 7, 8 and 9 show the effect of the strain-rate, along with correlations and prediction on base sheet (AA5182-O) samples with welds; a first generation (welding using standard welding parameters) and second

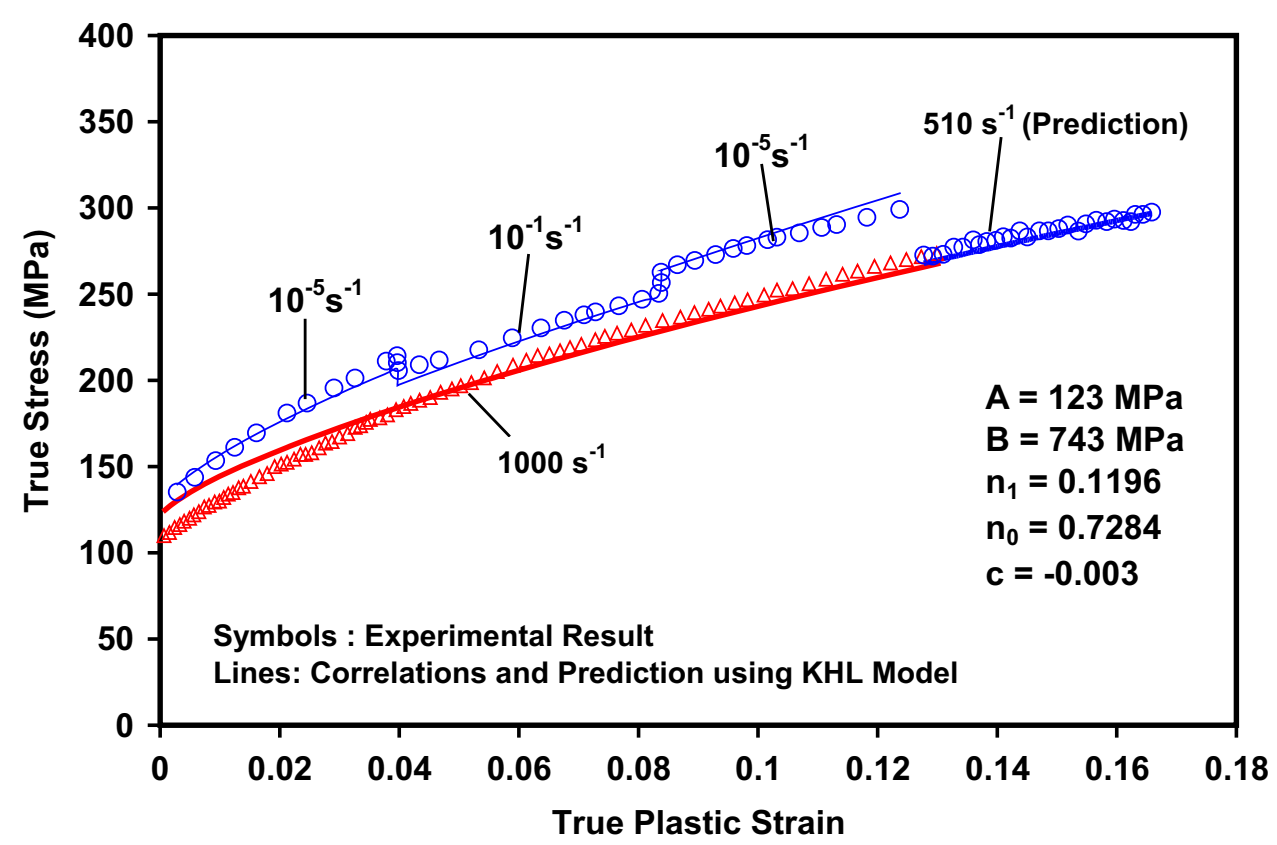

Fig. 5 True stress_-plastic strain responses of base sheet (AA5182-O) manufactured by DC process, with loading axis along the transverse to the rolling direction 
Fig. 6 True stress-plastic strain responses a at room temperature and $\mathbf{b}$ at high temperatures (with a constant strain rate of $\left.10^{-3} \mathrm{~s}^{-1}\right)$, of base sheet (AA5182-O)

manufactured by DC process, with loading axis along the rolling direction

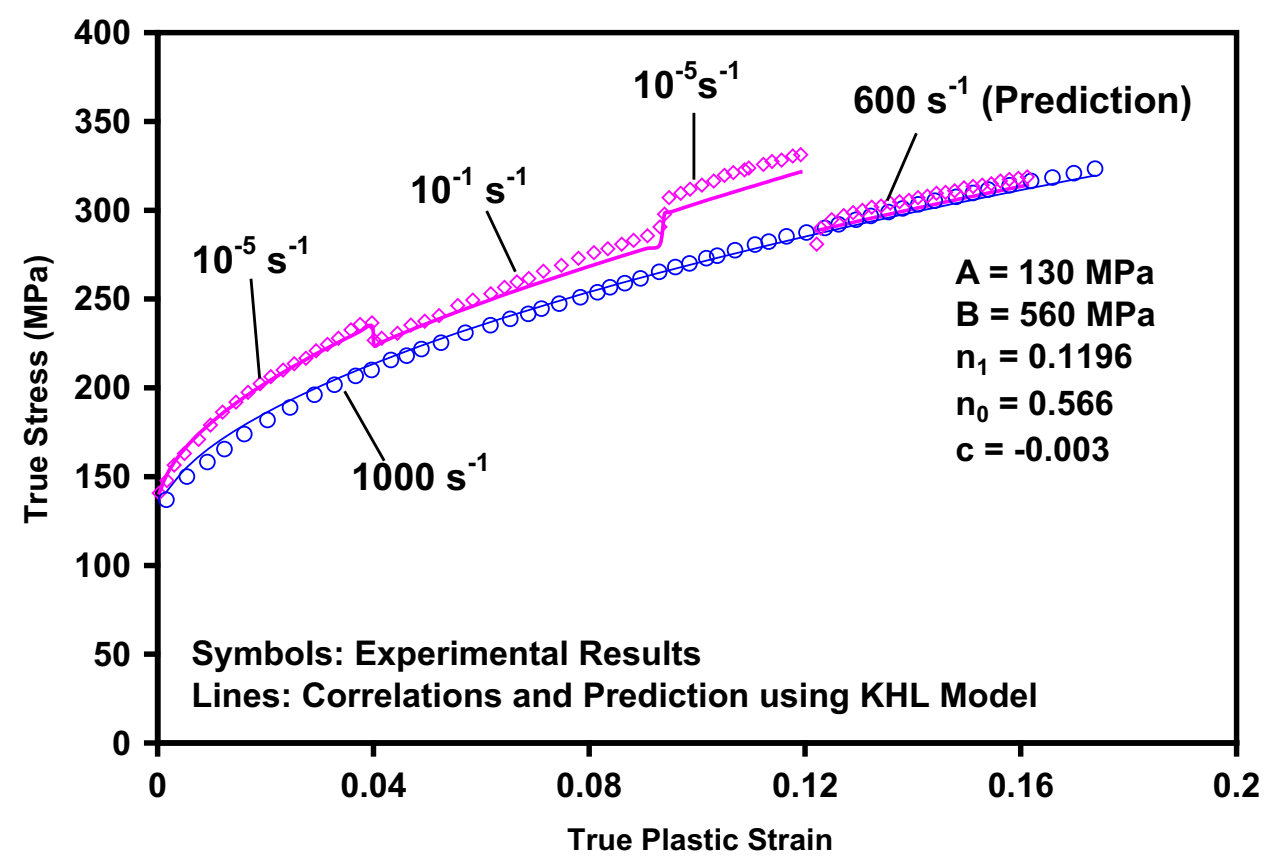

(a)

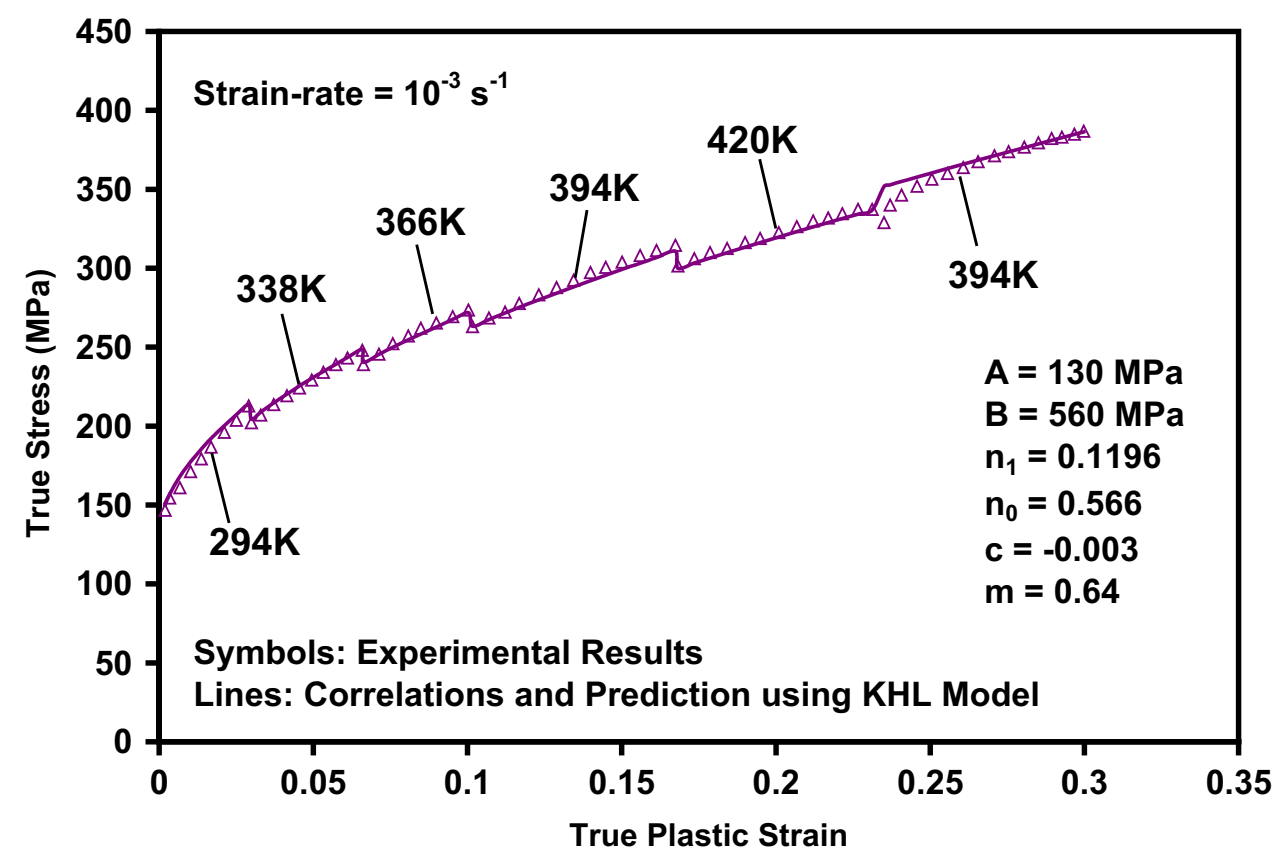

(b) generation (with optimized welding parameters) of gas tungsten arc welds (GTAW). These samples exhibit negative strain-rate sensitivity. On comparing Fig. 7 with Fig. 8 for DC processed material, the yield stresses of first generation GTAW specimen the welded samples are higher.

Figure 10a shows the experimental results along with correlations and prediction. These samples were made from FSW tailor welded blank consisting of $2 \mathrm{~mm}$ thick
AA5182-O sheet welded to a $1 \mathrm{~mm}$ thick base sheet (AA5182-O). The samples were made such that the loading direction is along the weld and almost $100 \%$ of the gage width represents the friction weld zone. It is observed that at room temperature, FSW-5182-O exhibit negative strainrate sensitivity as the base sheet material. However, the response (at room temperature) at different strain-rates suggests that the failure strain $(\sim 12 \%)$ is independent of strain-rate, which is different from the base sheet material 
Fig. 7 True stress-true plastic strain responses of first generation GTAW; specimen manufactured by DC process, with loading axis along the rolling direction
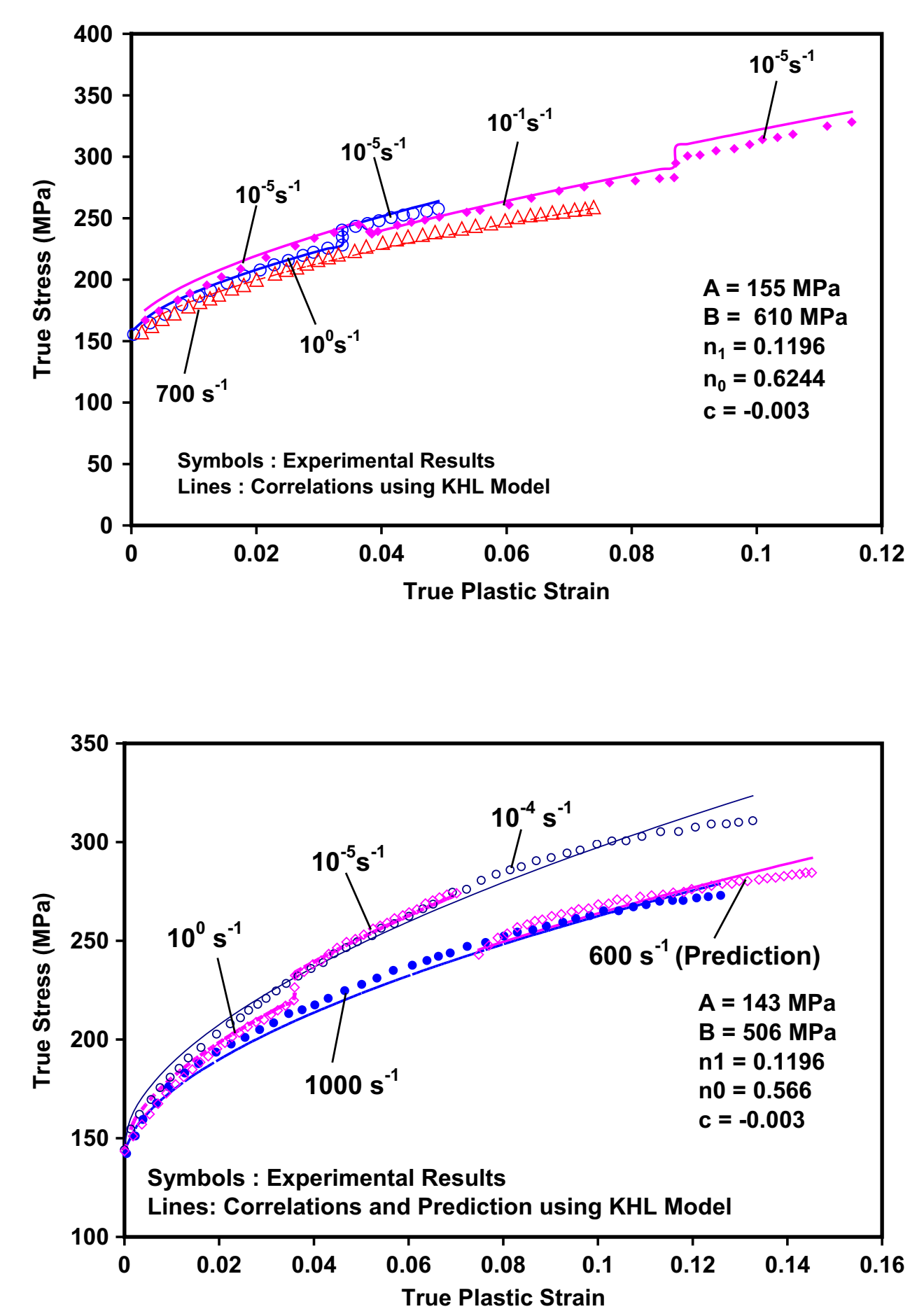

Fig. 8 True stress-true plastic strain responses of second generation GTAW specimen (manufactured by DC process), with loading axis along the rolling direction wherein the failure strain increases with strain-rate. Also, from the Fig. 10b the response of FSW-5182-O at different temperatures (at a constant strain rate of $10^{-3} \mathrm{~s}^{-1}$ ) shows the enhanced ductility from $12 \%$ at room temperature to about $23 \%$ at high temperature.

Figure 11 illustrates the experimental response of $\mathrm{Al}$ 6111-T4 at different strain-rates along with the correlations and prediction from the constitutive model. AL 6111-T4 showed positive strain-rate sensitivity. It was observed that the failure strain of AL 6111-T4 was higher than AA5182O. Also, the yield stress of AL 6111-T4 was observed to be higher than that of AA5182-O. Since the material exhibit positive strain-rate sensitivity, the material parameter $\mathrm{c}$ in the constitutive model is positive. 
Fig. 9 True stress-plastic strain responses 2 nd generation GTAW specimen manufactured by $\mathrm{CC}$ process, with loading axis along the rolling direction

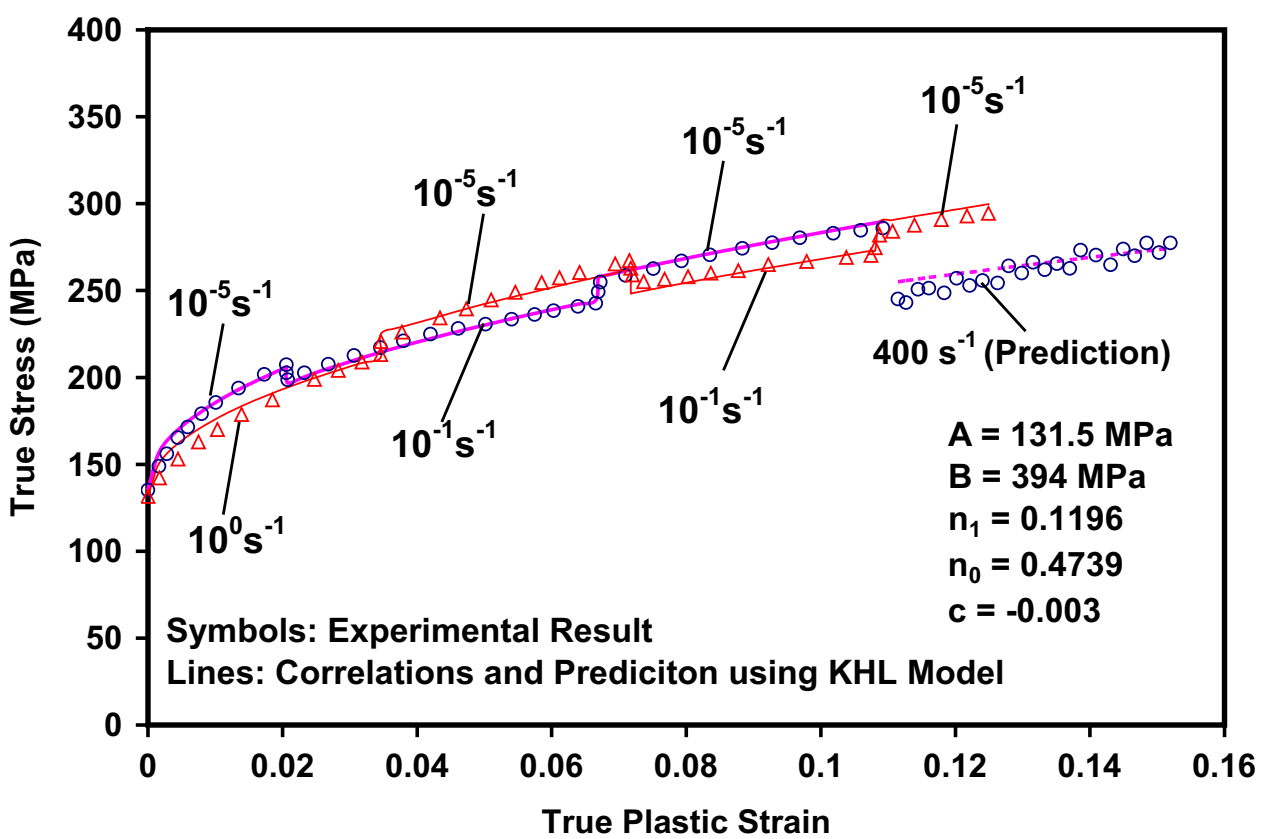

Figure 12 shows the inverse pole figure maps of AA5182-O sheets deformed at different strain rates. The micro-texture analysis was conducted at the cross sections (RD-ND) normal to the loading direction on the corresponding fractured samples. The color represents the crystallographic orientation parallel to the ND. It is observed that the initial grains are divided into smaller grains sections by uniaxial tension wherein; the grains are elongated in the loading direction which consequently results in reduction in the grain sections along normal directions. EBSD analysis indicates that the average grain size slightly reduced as the strain rate increases. It was shown that $\mathrm{ND} / /\langle 110\rangle$ texture components were enhanced by uniaxial tension.

Figure 13 represents $\varphi_{2}=45^{\circ}, 65^{\circ}$ and $90^{\circ}$ sections of orientation distribution functions (ODF) of AA5182-O sheet. Positions in Euler space of texture components typical in aluminum alloy sheets can be found in each section. Initial texture of the AA-5182-O sheet was identified as a mixture of rolling texture, i.e. the $\alpha$-fiber (from Goss $\{011\}\langle 100\rangle$ to Brass $\{011\}\langle 211\rangle$ ) and the $\beta$-fiber (from Brass $\{011\}\langle 211\rangle, \quad S\{123\}\langle 634\rangle$ to Copper $\{112\}\langle 111\rangle)$ and Cube $\{001\}\langle 100\rangle$, texture components. It was observed that Brass and Cube texture components are more stabilized in the deformed samples compared to other texture components. It should be noted that Copper texture component drastically decreased after uniaxial tension. The result indicates that Copper texture component kinematically unstable during uniaxial tension.

Figure 14 shows the inverse pole figure maps of AL6111-T4 sheets deformed at different strain rates. The micro-texture analysis was conducted at the cross sections (RD-ND) normal to the loading direction on the corresponding fractured samples. It was observed that the average grain size slightly reduced as the strain rate increases. This observation could be explained on the basis of the extent of deformation caused by increasing the strain-rate wherein; grain sections are elongated in the loading direction and consequently result in reduction in the grain section along the normal directions. The inverse pole figure map illustrates that micro-texture does not change significantly by uniaxial tension.

Figure 15 represents $\varphi_{2}=45^{\circ}, 65^{\circ}$ and $90^{\circ}$ sections of orientation distribution functions (ODF) of AA6111-T4 sheet. The symbols show the different texture components. The darker region corresponds to the most significant texture component present. The initial texture of the AL6111-T4 sheet was identified as a strong Cube texture component. It was observed that initial texture does not change significantly during uniaxial tension. The result indicates that Cube texture component relatively stable during uniaxial tension.

In the present study, rotation rate maps for the uniaxial tension deformation were calculated using the full-constraints polycrystal model (as mentioned in Constitutive Model and Theoretical Analysis section). Figure 16 shows the $\varphi_{2}=45^{\circ}, 65^{\circ}$ and $90^{\circ}$ sections of ODF that represent the rotation field maps for the AA5182-O sheet during uniaxial tension. The direction of the arrows represents the change in crystallographic orientation and the arrow length represents the total rotation rate. The stable orientation is that for which all direction of the arrows converge. It seems 
Fig. 10 True stress-plastic strain responses a at room temperature and $\mathbf{b}$ at high temperatures (with a constant strain rate of $\left.10^{-3} \mathrm{~s}^{-1}\right)$, of FSW-5182-O with loading axis along the rolling direction

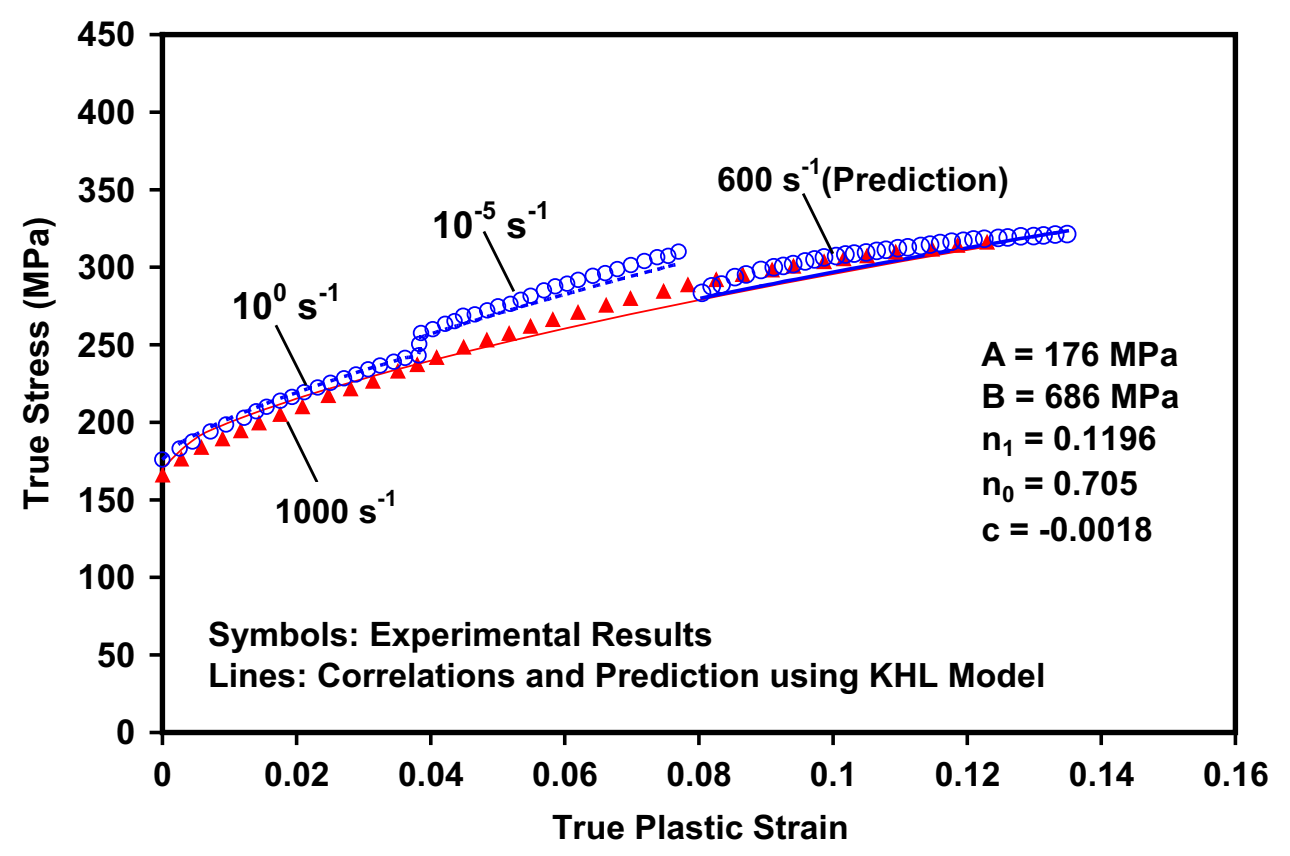

(a)

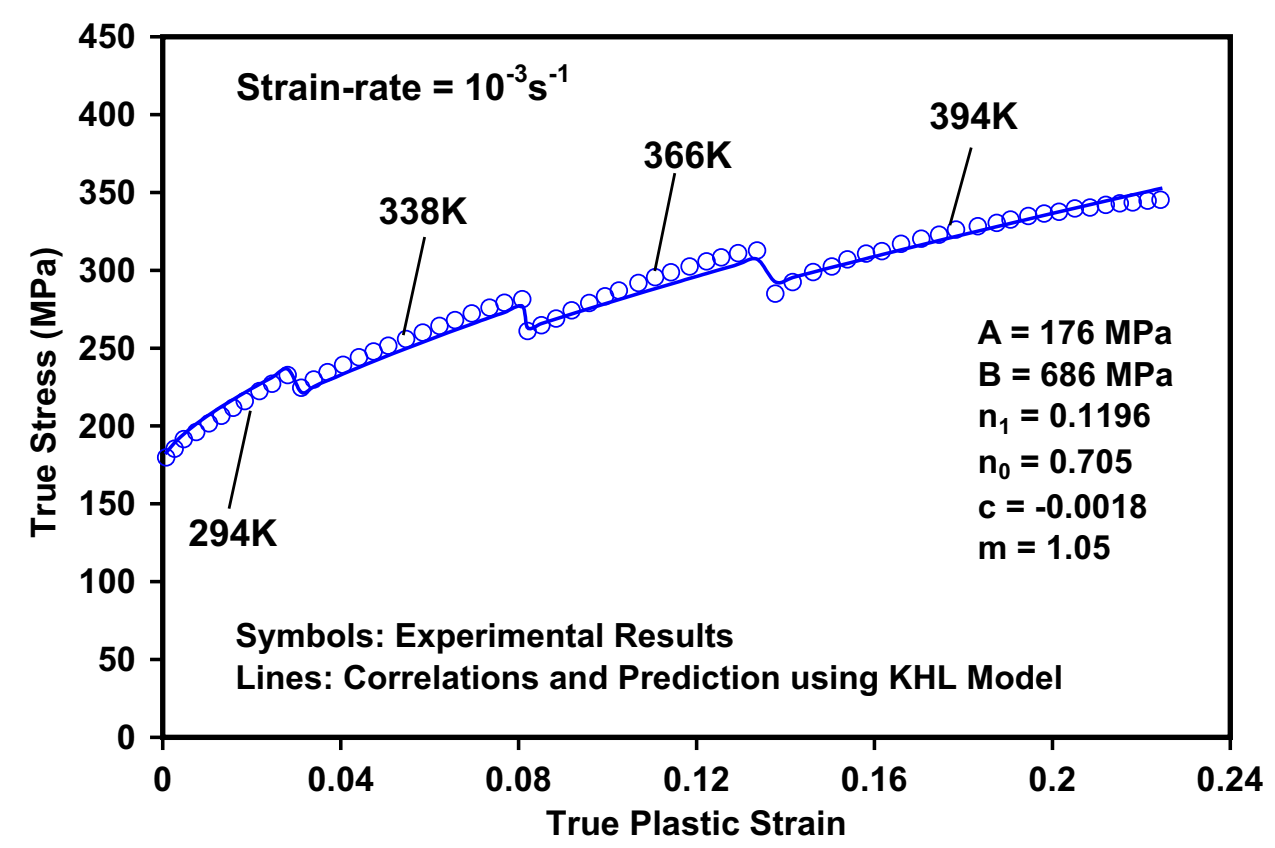

(b) that Brass texture component is relatively stable during the uniaxial tension, compared to the other texture components.

Figure 17 shows the $\varphi_{2}=45^{\circ}, 65^{\circ}$ and $90^{\circ}$ sections of ODF that represents the rotation field map for the AL6111T4 sheet during uniaxial tension. It seems that the different R-value in Eq. (2) does not affect the stable orientation during uniaxial tension significantly. To evaluate the kinematic stability of crystallographic orientation, the convergence and stability parameters were calculated using the full-constraints polycrystal model. In the present study, five texture components were selected to compare the kinematic stability of AA5182-O and AL6111-T4 sheets during uniaxial tension. Table 3 shows the rotation rate, gradient, divergence and relative stability of the five texture components under uniaxial tension of the AA5182-O 
Fig. 11 True stress-plastic strain response of AL6111-T4
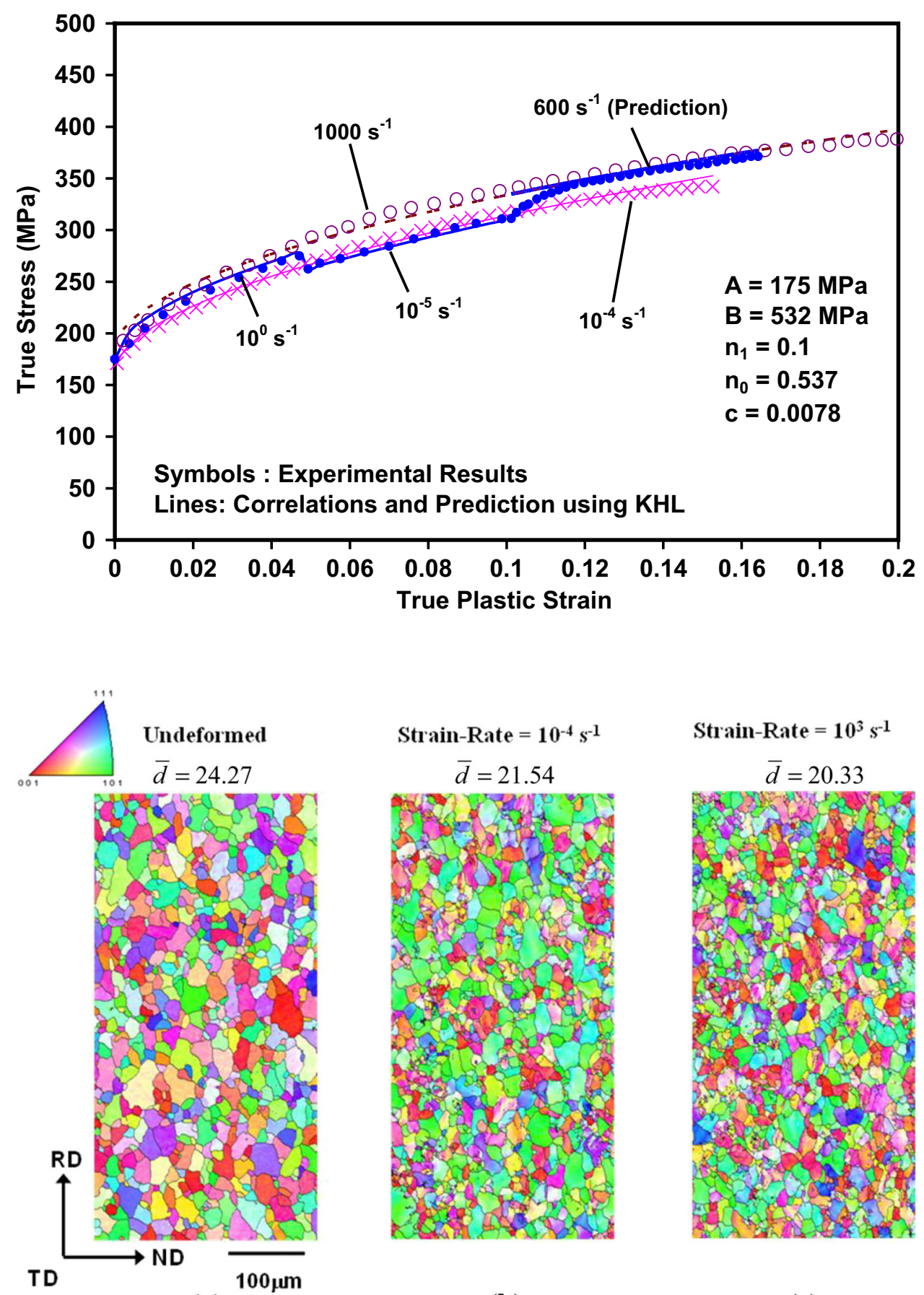

(a)

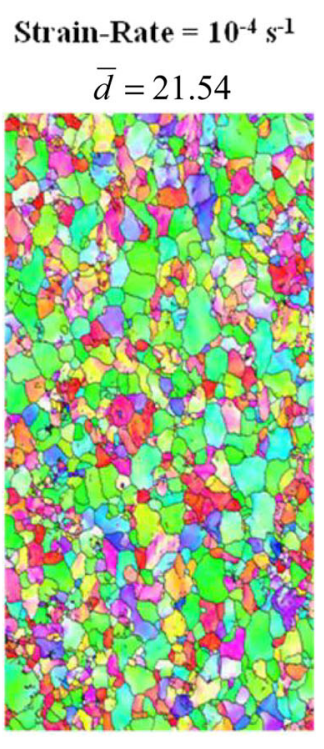

(b)

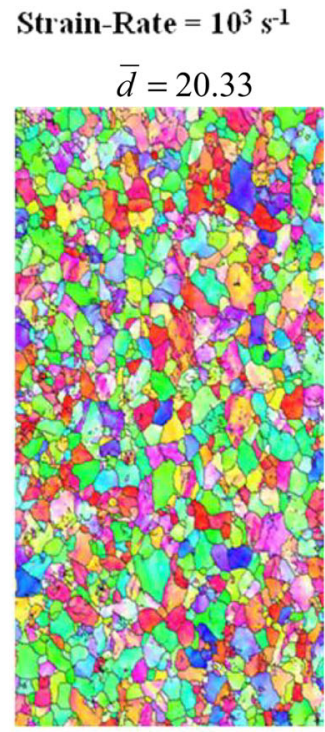

(c) sheet. Based on $\operatorname{div} \dot{\mathbf{g}}$ and S, Copper texture components were analyzed to be kinematically unstable under the uniaxial tension. Brass and Cube texture components were analyzed to be kinematically stable under the uniaxial tension. These two parameters explain why the Copper texture component drastically decreased at the AA5182-O sheet during uniaxial tension, as shown in Fig. 13. It seems that the low stability parameter contributed to the low intensity of the $\mathrm{S}$ texture component. Table 4 shows the rotation rate, gradient, divergence and relative stability of the orientations under uniaxial tension deformation of the AL6111-T4 sheet. It should be noted that the different $\mathrm{R}$-value contributed to a slight change of the convergence and stability parameters. The kinematically unstable and stable orientations were almost same with that of the AA5182-O sheet. Brass and Cube texture components were analyzed to be kinematically stable under the uniaxial tension. Copper and $\mathrm{S}$ texture components were analyzed 


\begin{tabular}{|c|c|c|c|c|}
\hline Brass & Copper & S & Goss & Cube \\
\hline$\circ$ & $\square$ & $\diamond$ & $\circ$ & 々 \\
\hline
\end{tabular}

\section{Undeformed}
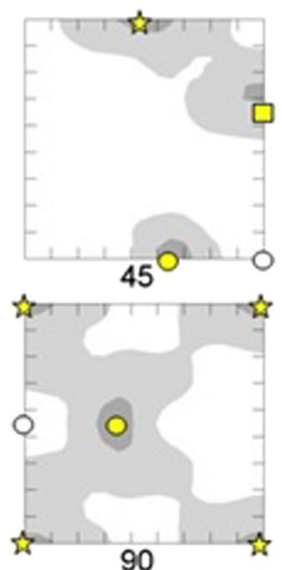

(a)
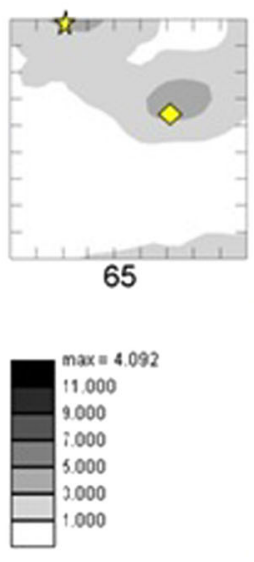

strain-rate $=10^{-4} \mathrm{~s}^{-1}$
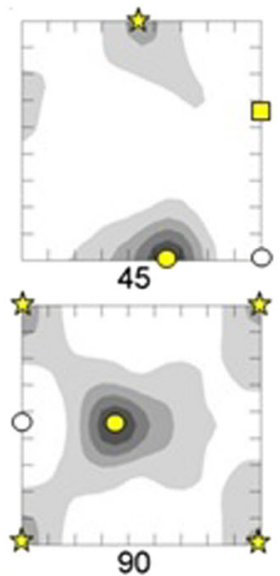

(b)
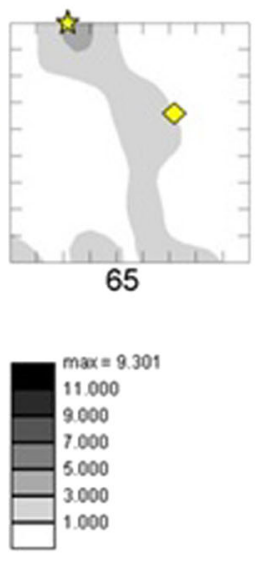

strain-rate $=10^{3} \mathrm{~s}^{-1}$
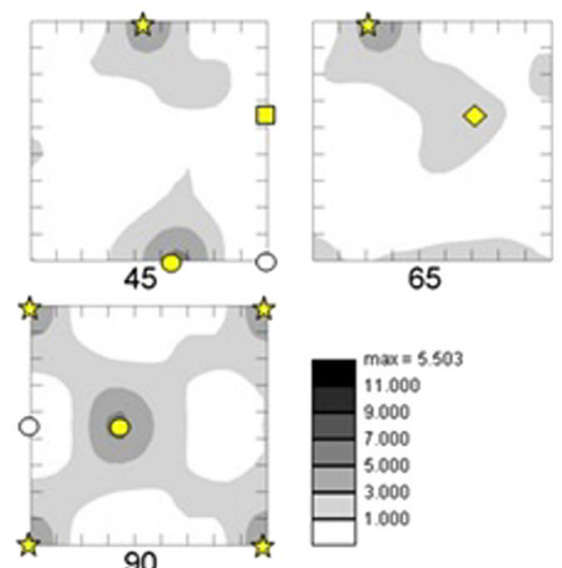

(c)

Fig. $13 \varphi_{2}=45^{\circ}, 65^{\circ}$ and $90^{\circ}$ sections of ODF for AA5182-O sheets deformed at different strain rates: a undeformed, b $10^{-4} \mathrm{~s}^{-1}, \mathbf{c} 10 \mathrm{~s}^{-1}$

Fig. 14 Inverse pole figure map of AL6111-T4 sheets deformed at different strain rates: a undeformed, b $10^{-4} \mathrm{~s}^{-1}$, c $10^{3} \mathrm{~s}^{-1}$

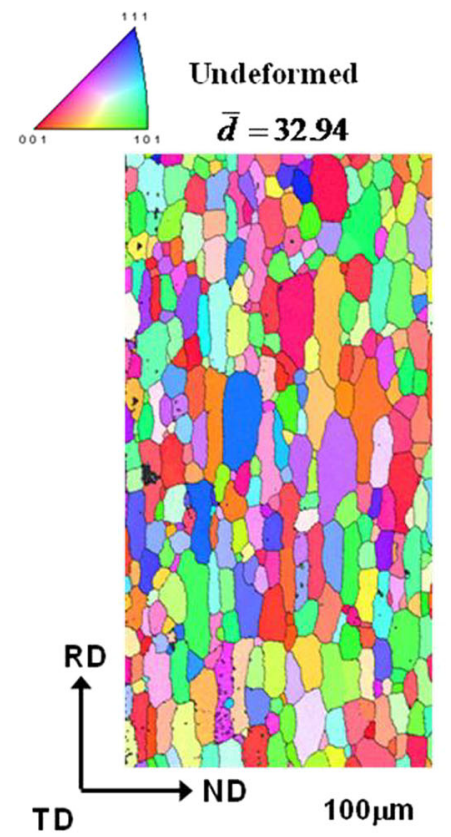

(a)

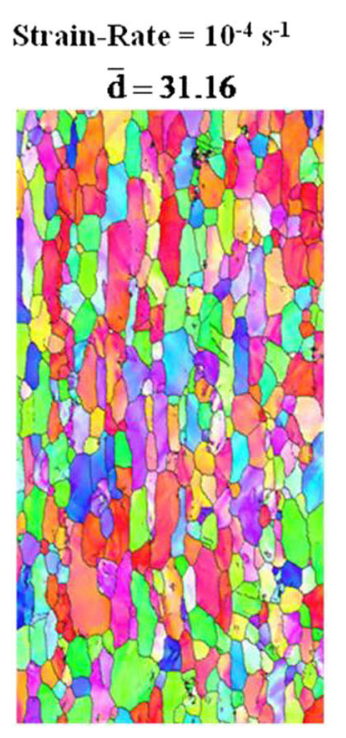

(b)

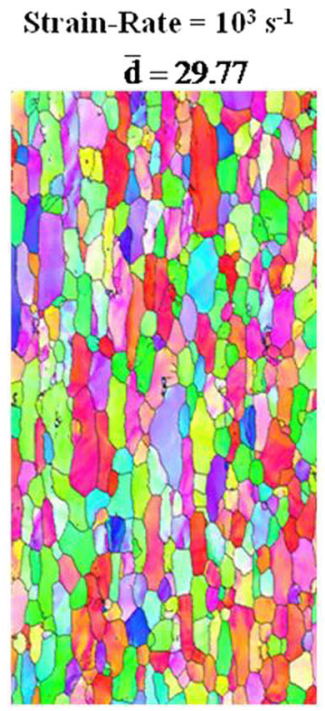

(c) as kinematically unstable orientations under the uniaxial tension. Since the initial Cube texture component is kinematically stable, it seems that the Brass texture components did not exhibit a significant texture change during uniaxial tension.

\section{Conclusions}

In the present study, a series of quasi-static and dynamic experiments on AA5182-O and AL6111-T4 at different strain-rates were presented. The materials investigated 


\begin{tabular}{|c|c|c|c|c|}
\hline Brass & Copper & S & Goss & Cube \\
\hline$\circ$ & $\square$ & $\diamond$ & $\circ$ & $\diamond$ \\
\hline
\end{tabular}

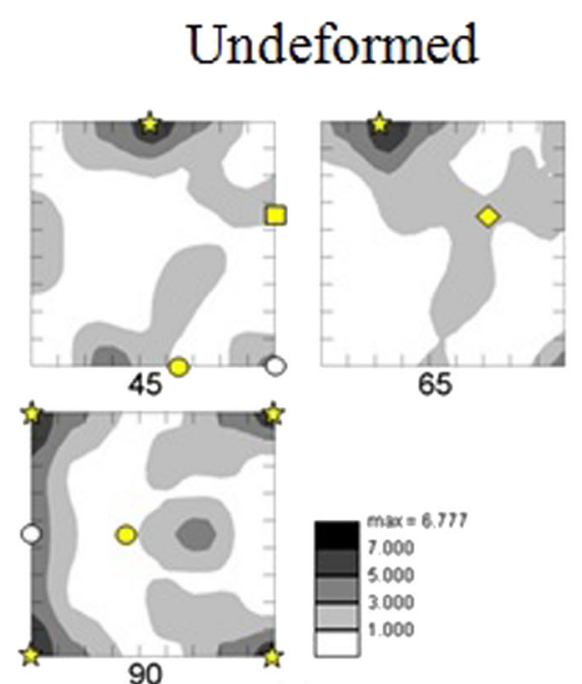

(a)
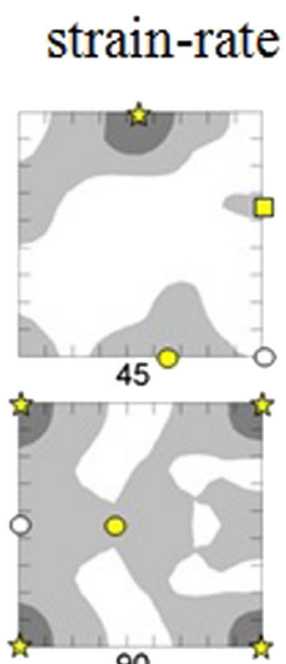

90
$=10^{-4} \mathrm{~s}^{-1}$
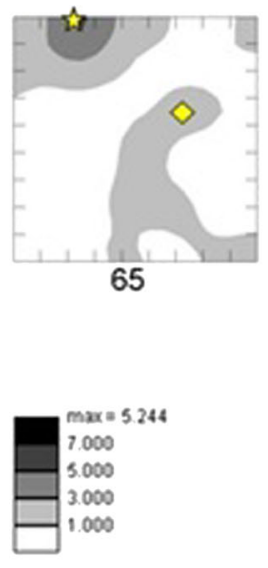

(b)

\section{strain-rate $=10^{3} \mathrm{~s}^{-1}$}
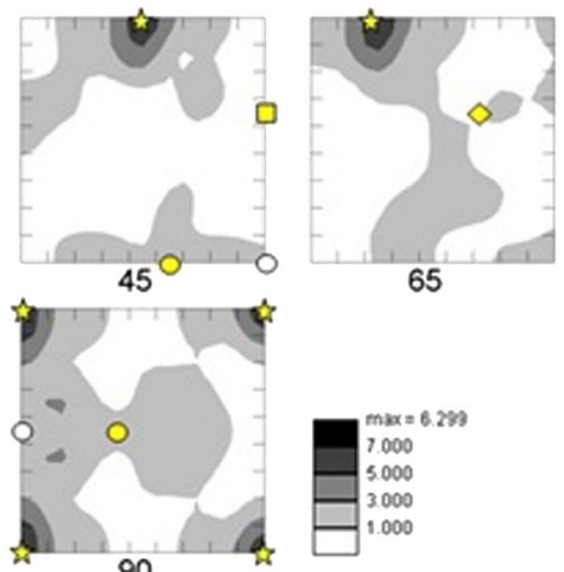

90

Fig. $15 \varphi_{2}=45^{\circ}, 65^{\circ}$ and $90^{\circ}$ sections of ODF for AL6111-T4 sheets deformed at different strain rates: a undeformed, b $10^{-4} \mathrm{~s}^{-1}, \mathbf{c} 10^{3} \mathrm{~s}^{-1}$
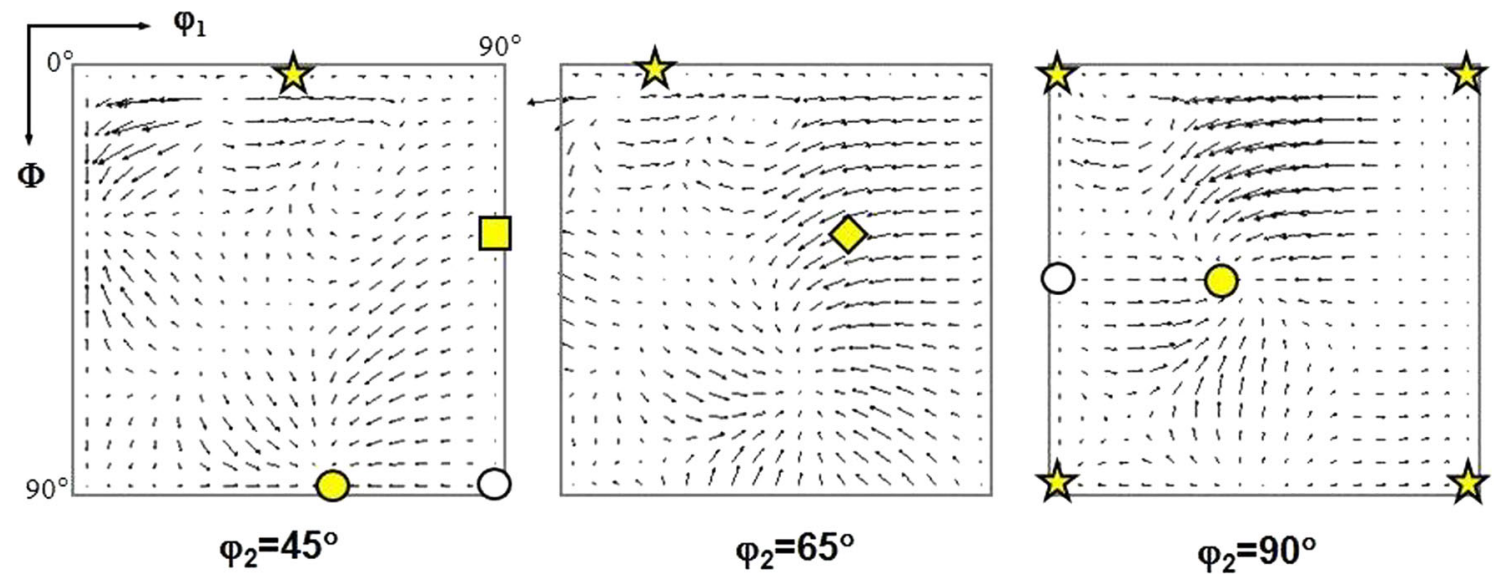

Fig. 16 Rotation rate maps in the $\varphi_{2}=45^{\circ}, 65^{\circ}$ and $90^{\circ}$ section for uniaxial tension of AA5182-O sheet

include the first and second generations of GTAW, as well as friction welds. These experiments were performed over wide range of strain rates from $10^{-5}$ to $10^{3} \mathrm{~s}^{-1}$ at room temperature. In this investigation, the tensile split Hopkinson pressure bar was modified to secure the thin sheet dog-bone specimens to the incident and transmitted bars. This was done to reduce the wave distortion during the experiment. AA5182-O, and first and second generation of GTAW showed negative strain rate sensitivity; the FSW samples did not show any significant sensitivity to strain-rate. AL6111-T4 showed positive strain rate sensitivity. Correlations and predictions from the KHL constitutive model were in good agreement with the experimental results. The texture evolution of the AA5182-O and AL6111-T4 sheets during uniaxial tension was investigated using EBSD technique and full-constraints polycrystal model. EBSD analysis reveals that stable orientation is strongly dependent on the initial texture components. It was found that Brass texture component is stable and Copper texture component is unstable in the AA5182-O sheet during uniaxial tension along the TD. The convergence 

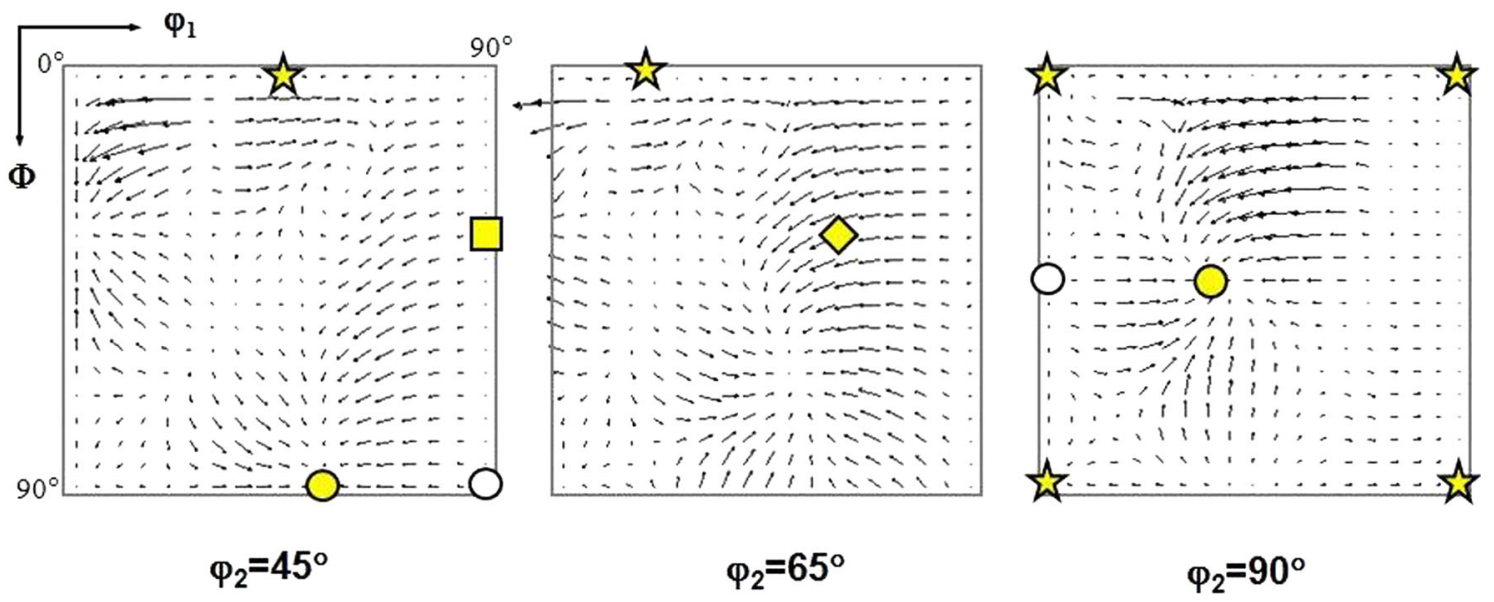

Fig. 17 Rotation rate maps in the $\varphi_{2}=45^{\circ}, 65^{\circ}$ and $90^{\circ}$ section for uniaxial tension of AL6111-T4 sheet

Table 3 Rotation rate, gradient, divergence and relative stability of the five texture components under uniaxial tension of the AA5182-O sheet

\begin{tabular}{lclrcr}
\hline & Brass & Copper & \multicolumn{1}{l}{ S } & Goss & Cube \\
\hline$\dot{\phi}_{1}$ & -0.11 & 0 & -0.94 & 0 & 0.84 \\
$\dot{\Phi}$ & 0 & 0.03 & 0.53 & 0 & -0.01 \\
$\dot{\phi}_{2}$ & 0 & 0 & 0.97 & 0 & -0.84 \\
$\frac{\partial \dot{\phi}_{1}}{\partial \phi_{1}}$ & -2.19 & 1.36 & 0.27 & 0.4 & -0.5 \\
$\frac{\partial \dot{\Phi}}{\partial \Phi}$ & -1.19 & 0.28 & 0.45 & -0.52 & -1.17 \\
$\frac{\partial \dot{\phi}_{2}}{\partial \phi_{2}}$ & 0.75 & 0.21 & -3.18 & 1.59 & -1.4 \\
$\operatorname{div} \dot{\mathbf{g}}$ & -2.63 & 1.85 & -2.96 & 1.48 & -3.07 \\
$\mathrm{~S}$ & 2.18 & 3.41 & 0.23 & 8.59 & 3.92 \\
\hline
\end{tabular}

Table 4 Rotation rate, gradient, divergence and relative stability of the orientations under uniaxial tension deformation of the AL6111-T4 sheet

\begin{tabular}{lccccc}
\hline & Brass & Copper & \multicolumn{1}{l}{ S } & Goss & Cube \\
\hline$\dot{\phi}_{1}$ & -0.04 & 0 & -0.92 & 0 & 0.78 \\
$\dot{\Phi}$ & 0 & 0.01 & 0.49 & 0 & -0.01 \\
$\dot{\phi}_{2}$ & 0 & 0 & 0.86 & 0 & -0.78 \\
$\frac{\partial \dot{\phi}_{1}}{\partial \phi_{1}}$ & -2.34 & -1.07 & -0.09 & 2.41 & -1.1 \\
$\frac{\partial \dot{\Phi}}{\partial \Phi}$ & -0.93 & -0.11 & 0.3 & -0.04 & -0.73 \\
$\frac{\partial \dot{\phi}_{2}}{\partial \phi_{2}}$ & -1.92 & 6.72 & 1.68 & -0.7 & -0.67 \\
$\operatorname{div} \dot{\mathbf{g}}$ & -5.18 & 5.54 & 1.89 & 1.67 & -2.5 \\
$\mathrm{~S}$ & 3.13 & 4.23 & 0.29 & 8.88 & 3.96 \\
\hline
\end{tabular}

and stability parameters can explain why the Copper texture component drastically decreased in the AA5182$\mathrm{O}$ sheet during uniaxial tension. EBSD analysis also revealed that Cube texture component is stable and a significant texture change did not occur in the AL6111T4 sheet. It was concluded that the relatively high stability of Cube texture component contributed to the slight change of texture during uniaxial tension.

Acknowledgments The authors gratefully acknowledge the partial funding of this project by Pacific Northwest National Laboratory (PNNL) through Mr. Richard Davies.

\section{References}

1. Picu RC, Vincze G, Ozturk F, Gracio JJ, Barlat F, Maniatty AM (2005) Strain rate sensitivity of the commercial aluminum alloy AA5182-O. Mater Sci Eng 390:334-343

2. Kinsey B, Viswanathan V, Cao J (2001) Forming of Aluminum Tailor Welded Blanks. J Mater Manuf 110:673-679

3. Ayres RA (1979) Alloying aluminum and magnesium for ductility at warm temperatures. Met Trans A 10:849-854

4. Li D, Ghosh AK (2003) Biaxial warm forming behavior of aluminum sheet alloys. J Mater Process Technol 145:281-293

5. Li D, Ghosh AK (2003) Tensile deformation behavior of aluminum alloys at warm forming temperatures. Mater Sci Eng 352:279-286

6. Abedrabbo N, Pourboghrat F, Carsley J (2007) Forming of AA5182-O and AA5754-O at elevated temperatures using coupled thermo-mechanical finite element models. Int $\mathrm{J}$ Plast 23:841-875

7. Abedrabbo N, Pourboghrat F, Carsley J (2006) Forming of aluminum alloys at elevated temperatures-Part 1: material characterization. Int J Plast 22:314-341

8. Abedrabbo N, Pourboghrat F, Carsley J (2006) Forming of aluminum alloys at elevated temperatures-Part 2: numerical modeling and experimental verification. Int J Plast 22:342-373

9. Hughes DA, Kassner ME, Stout MG, Vetrano JS (1998) Metal forming at the center of excellence for the synthesis and processing of advanced materials. JOM 50(6):16-21

10. Davies RW, Grant G, Khaleel MA, Smith MT, Oliver HE (2001) Forming- limit diagrams of aluminum tailor-welded blank weld material. Metall Mater Trans A 32(2):275-283

11. Kolsky H (1949) Stress waves in solids. Dover, New York 
12. Kang WJ, Cho SS, Huh H, Chung DT (1998) Identification of dynamic behavior of sheet metals for an auto-body with tension split Hopkinson bar. SAE Trans J Mater Manuf 107:908-913

13. Harding J, Wood EO, Campbell JD (1960) Tensile testing of materials at impact rates of strain. J Mech Eng Sci 2:88-96

14. Hauser FR (1966) Technique for measuring stress-strain relation at high strain rate. Exp Mech 6:395-402

15. Lindholm US, Yeakly LM (1968) High strain-rate testing: tension and compression. Exp Mech 8:1-9

16. Lindholm US (1971) High strain rate tests. In: Bunshah RF (ed) Techniques of metals research, vol 5, 1st edn. Wiley, Hoboken

17. Nicholas T (1981) Tensile testing of materials at high rates of strain. Exp Mech 21(5):177-185

18. Nicholas T (1982) Material Behavior at High Strain Rates. In: Zukas JA, Swift HF, Greszczuk LB, Curran (eds) Impact Dynamics, vol 8. Wiley, Hoboken

19. Huh H, Kang WJ, Han SS (2002) A tension split Hopkinson bar for investigating the dynamic behavior of sheet metals. Exp Mech 42(1):8-17

20. Staab GH, Gilat A (1981) A direct-tension split Hopkinson bar for high strain-rate testing. Exp Mech 31:232-235
21. Toth LS, Jonas JJ, Gilormini P, Bacroix B (1990) Length changes during free end torsion: a rate sensitive analysis. Int $\mathrm{J}$ Plast 6:83-108

22. Choi SH, Cho JH, Oh KH, Chung KS, Barlat F (2000) Texture evolution of FCC sheet metals during deep drawing process. Int J Mech Sci 42:1571-1592

23. Khan AS, Liang R (1999) Behavior of three BCC metal over a wide range of strain rates and temperatures. Int $\mathrm{J}$ Plast 15:1089-1109

24. Khan AS, Suh YS, Kazmi R (2004) Quasi-static and dynamic loading responses and constitutive modeling of titanium alloys. Int J Plast 20:2233-2248

25. Khan AS, Kazmi R, Farrokh B (2007) Multiaxial and non-proportional loading responses, anisotropy and modeling of Ti-6Al$4 \mathrm{~V}$ titanium alloy over wide ranges of strain rates and temperatures. Int J Plast 23:931-950

26. Choi SH, Brem JC, Barlat F, Oh KH (2000) Macroscopic anisotropy in AA5019A sheets. Acta Mater 44:1853-1863

27. Choi SH, Han SH, Chin KG (2009) Simulation of orientation gradients in a ferrite matrix containing hard martensite under plane-strain flange deformation. Acta Mater 57:1947-1958 